\title{
Selection of priority areas for arthropod conservation in the Azores archipelago
}

\author{
Clara Gaspar • Kevin J. Gaston • Paulo A. V. Borges • \\ Pedro Cardoso
}

Received: 14 July 2010/Accepted: 23 October 2010/Published online: 11 November 2010

(C) Springer Science+Business Media B.V. 2010

\begin{abstract}
The largest standardised database available to date for arthropods in native forests of the Azores archipelago was used to determine the minimum optimal set of native forest fragments needed to accomplish four different targets of species occurrence (presence-absence) and abundance $(20,50$ and $80 \%)$ using different groups of arthropods and all data combined. The results showed that occurrence and $20 \%$ abundance targets gave similar optimal solutions for most of the groups considered. At least one fragment on each of the seven studied islands was required to accomplish any occurrence and abundance target. To achieve $80 \%$ of abundance for all species, all fragments were necessary and to guarantee $50 \%$ of the overall abundance of endemics, 17 out of 18 native forests were needed. A suggestion is made to apply a measure of biotic integrity related to disturbance to select, among alternative optimal solutions, the set of areas that will help to guarantee the viability of populations. Some guidelines for the selection of priority areas for conservation in the Azores are presented.
\end{abstract}

C. Gaspar $(\varangle)$ · P. A. V. Borges - P. Cardoso

Azorean Biodiversity Group (CITA-A), Departamento de Ciências Agrárias, Universidade dos Açores, Terra-Chã, 9701-851 Angra do Heroísmo, Terceira, Azores, Portugal e-mail: cgaspar@ennor.org

C. Gaspar · K. J. Gaston

Biodiversity and Macroecology Group, Department of Animal and Plant Sciences, University of Sheffield,

Sheffield S10 2TN, UK

P. Cardoso

Smithsonian Institution, National Museum of Natural History, Washington, DC 20013-7012, USA
Keywords Arthropods - Azores · Complementarity · Irreplaceability · Optimisation algorithm · Reserve selection

\section{Introduction}

It is now widely recognized that the conservation of biodiversity requires urgent, effective and low cost measures (e.g. Balmford and Whitten 2003; Frazee et al. 2003; Strange et al. 2006). Conservationists have to deal with a growing number of constraints, whether economic, political, social or cultural, while biodiversity is increasingly threatened (e.g. Nantel et al. 1998). A prevailing approach to preserve biodiversity is the selection and local negotiation of priority areas with a high biodiversity value and where human activities and disturbance factors can best be controlled.

The science of reserve selection and design as an interdisciplinary field is relatively new, having only become well established over the last two to three decades (see Kingsland 2002 for a review) but it has developed considerably in the last decade. Two main methods have been used for the selection of priority areas: (1) scoring techniques, where one or more criteria are used to attribute a given value to an area, and areas are ranked based directly on those values (see Margules and Usher 1981 for a review) and (2) complementarity methods, where areas are chosen based on the degree of dissimilarity prevailing among them, whether by a sequential choice of areas (suboptimal complementarity) or a selection of a minimum set of areas (optimal complementarity; defined by VaneWright et al. 1991, see Justus and Sarkar 2002 for a review). Complementarity-based methods have developed greatly, and are at present the most common techniques to 
select priority areas for conservation in many theoretical exercises. Here, these methods are applied to native forests in the Azores.

The Azores archipelago has a particular type of subtropical native forest, believed by many authors to be a relict of the Laurel forest that covered the Mediterranean Basin during the Tertiary (Dias 1996, but see Emerson 2002). Laurisilva only occurs in a few oceanic islands of the North Atlantic Macaronesia region (comprising Azores, Madeira, Savage, Canaries and Cape Verde archipelagos), with particular fauna and flora in each archipelago. The Azorean Laurisilva is characterized by a dense cover of shrub and tree species of small stature, a rich cover of bryophytes, low understorey light and high levels of humidity. It has a high proportion of endemic vascular plant and invertebrate species (mostly arthropods and molluscs), while vertebrates (many introduced) are poorly represented (see Borges et al. 2005b, 2010).

The Azorean islands were mostly covered by this native forest 550 years ago when human settlements were first established in the islands. Since then, the forest has been greatly reduced, fragmented and disturbed by logging, clearance for agricultural activities and by the introduction of invasive plant and animal species. At present, Laurisilva is restricted to fragments in high and steep areas in seven out of the nine major islands of the archipelago. Although this type of forest covers less than $3 \%$ of the total area of the archipelago, it is the biotope in which the great majority of the endemic plant and animal species occur in the Azores (Borges et al. 2005b, 2008; Cardoso et al. 2009).

In 1988, the importance of this biotope was recognized and some of the native forest fragments were included in partial Natural Forest Reserves (NFRs), managed by the Regional Directorate for Forest Resources. Later, in 2004, some parts of the native forest areas were included into Sites of Community Interest (SCIs), to be converted in Special Areas for Conservation (SACs), and into Special Protection Areas (SPAs). The SACs and SPAs would then contribute to the Natura 2000 network. The SACs and SPAs would have their own statutory laws that would differ from those approved for the NFRs even for the areas that overlapped (DRA 2004). While some fragments showed overlapping protection, others were not included under any of the designations. In order to overcome the multiple definitions, aims, priorities and laws applied to each area, the Regional Secretariat for the Environment and the Sea (RSES) and the University of the Azores discussed in 2007 a reclassification of the protected areas according to the widely used IUCN category system. Most of the forest fragments are now being included in Island Nature Parks. However, the managers of each Island Nature park (from the RSES) are still being appointed and the management plans, taking into account the protection categories within each area, will take several years to be defined and to put into practice.

Before the suggested reclassification based on IUCN criteria, the choice of areas to protect in the Azores has focused on biotopes, rare vascular plants and a few vertebrates. Invertebrates, and in particular arthropods, the most diverse and abundant known phylum occurring in all Azorean terrestrial biotopes, were neglected, partly due to the paucity of data that were available for this group. In the last few years, however, great efforts have been made to inventory and map the arthropod diversity in native forests and other biotopes (see Borges et al. 2005a, 2008; Gaspar et al. 2008; Cardoso et al. 2009). The suggested reclassification has taken into account some of these recent arthropod data, but clear proposals for reserve design and management plans of the most abundant and diverse terrestrial known group of the Azores are lacking. First attempts to rank and select protected areas in the Azores using arthropods were made by Borges et al. (2000, 2005a) using literature data and epigean endemics (respectively). Additional sampling effort has been applied in native forests since then and more information on arthropod distribution has become available.

In this study, the largest standardised database available to date for arthropods in remnants of the Azorean native forest was used to:

(a) Determine the minimum set of forest fragments needed to accomplish four different targets (species occurrence and three levels of population abundance) using the entire dataset and several categorizations (taxonomic classification, trophic role, colonization status, vertical distribution in the forest patches and dispersal ability);

(b) Evaluate the irreplaceability of each native forest fragment;

(c) Complement the optimal alternative solutions (sets of fragments selected) with a measure of biotic integrity, thereby refining the solutions; and

(d) Give some recommendations on procedures for the selection of areas for biodiversity conservation in the Azores, which may have application to other oceanic archipelagos and habitat islands.

\section{Methods}

Study area

The remote North Atlantic archipelago of the Azores $\left(37-40{ }^{\circ} \mathrm{N}, 25-31{ }^{\circ} \mathrm{W}\right)$ has nine islands and islets with a total area of 225,000 ha. It is of recent volcanic origin (0.30-8.12 million years old) and experiences frequent 
seismic and volcanic activity. Climate is temperate humid at sea level and cold oceanic at higher altitudes. The atmospheric humidity is high with small temperature fluctuations throughout the year.

Eighteen native forest fragments distributed across seven islands of the archipelago were studied (Table 1). This corresponds to most of the native forest extent of the Azores. The areas excluded are small patches of less than 5 ha, highly fragmented, at low altitudes and/or strongly disturbed by cattle and invasive plants. Previous studies in some of these small patches indicate that they have a poor native fauna with a high occurrence of introduced species (Borges et al. unpublished data), so these fragments were not considered in this study. Native forest fragments vary in area (Table 1), isolation from the nearest fragments, geological age of soil (lava) substrate, altitude, plant species composition and structure (see Gaspar et al. 2008 for more details), and also in their biotic integrity (as defined by Cardoso et al. 2007). Terceira island alone contains almost half of the total area of native forest cover of the archipelago (Table 1). The fragments FLMO from Flores island and TESB from Terceira island (codes in Table 1) are the largest of the whole region. They have the same protection status and suggested IUCN category (Table 1).

\section{Sampling protocol}

A total of 72 transects, each $150 \mathrm{~m}$ long and $5 \mathrm{~m}$ wide, were randomly established in the 18 native forest fragments considered. The number of transects (four) was the same in all fragments, irrespective of the fragment area. Transects were performed during a summer month of 1999-2004. Several logistical constraints (e.g. difficult progress through the vegetation, rapid weather change, isolation of the islands) impeded that all sampling scheme could be accomplished in the summer of a single year. However, a complementary study regarding the efficiency of the sampling methods and effort used to assess arthropod diversity in Azorean native forests (Gaspar et al. data to be published) did not find significant differences on the

Table 1 Contribution of each fragment and island studied (\% forest) to the total native forest cover of the archipelago and protection status defined for each fragment

\begin{tabular}{|c|c|c|c|c|c|c|c|c|}
\hline Island & Fragment & Code & Area (ha) & $\%$ forest & NFR & SPA & SCI & IUCN \\
\hline \multirow[t]{3}{*}{ Flores } & & FL & 14102 & 27.4 & & & & \\
\hline & Morro Alto e Pico da Sé & FLMO & 1331 & 23.2 & $\bullet$ & & $\bullet$ & $\mathrm{I}, \mathrm{V}$ \\
\hline & Caldeiras Funda e Rasa & FLFR & 240 & 4.2 & $\bullet$ & & & IV \\
\hline \multirow[t]{3}{*}{ Faial } & & FA & 17306 & 3.9 & & & & \\
\hline & Caldeira do Faial & FACA & 190 & 3.3 & & $\bullet$ & $\bullet$ & I \\
\hline & Cabeço do Fogo & FACF & 36 & 0.6 & $\bullet$ & $\bullet$ & $\bullet$ & IV \\
\hline \multirow[t]{4}{*}{ Pico } & & PI & 44498 & 16.6 & & & & \\
\hline & Mistério da Prainha & PIMP & 689 & 12.0 & $\bullet$ & $\bullet$ & $\bullet$ & I \\
\hline & Caveiro & PICA & 184 & 3.2 & $\bullet$ & $\bullet$ & $\bullet$ & $\mathrm{I}, \mathrm{V}$ \\
\hline & Lagoa do Caiado & PILC & 79 & 1.4 & $\bullet$ & $\bullet$ & $\bullet$ & IV \\
\hline \multirow[t]{3}{*}{ S. Jorge } & & SJ & 24365 & 5.1 & & & & \\
\hline & Topo & SJTO & 220 & 3.8 & & & $\bullet$ & $\mathrm{V}$ \\
\hline & Pico Pinheiro & SJPI & 73 & 1.3 & & & $\bullet$ & $\mathrm{V}$ \\
\hline \multirow[t]{6}{*}{ Terceira } & & $\mathrm{TE}$ & 40030 & 40.9 & & & & \\
\hline & S. Bárbara e M. Negros & TESB & 1347 & 23.5 & $\bullet$ & & $\bullet$ & $\mathrm{I}, \mathrm{V}$ \\
\hline & Biscoito da Ferraria & TEBF & 557 & 9.7 & $\bullet$ & & $\bullet$ & $\mathrm{I}, \mathrm{V}$ \\
\hline & Guilherme Moniz & TEGM & 223 & 3.9 & & & & \\
\hline & Terra Brava & TETB & 180 & 3.1 & & & $\bullet$ & $\mathrm{V}$ \\
\hline & Pico do Galhardo & TEPG & 38 & 0.7 & & & & $\mathrm{~V}$ \\
\hline \multirow[t]{4}{*}{ S. Miguel } & & MI & 74456 & 5.8 & & & & \\
\hline & Pico da Vara & MIPV & 306 & 5.3 & $\bullet$ & $\bullet$ & & I \\
\hline & Graminhais & MIGR & 15 & 0.3 & $\bullet$ & $\bullet$ & & IV \\
\hline & Atalhada & MIAT & 10 & 0.2 & $\bullet$ & & & IV \\
\hline \multirow[t]{2}{*}{ Sta. Maria } & & MA & 9689 & 0.2 & & & & \\
\hline & Pico Alto & MAPA & 9 & 0.2 & & & & IV \\
\hline
\end{tabular}

Corvo and Graciosa islands do not have remnants of native forest and were not considered in this study

NFR Natural Forest Reserve, SPA Special Protected Area, SCI Site of Community Interest, IUCN categories I to VI 
arthropod diversity and composition of transects sampled in different years.

Arthropods from the soil (mainly epigean) and low vegetation were surveyed with a set of pitfall traps. Canopy arthropods from woody shrub and tree species were sampled using a beating tray. Along each transect, 30 pitfall traps (plastic cups with $4.2 \mathrm{~cm}$ diameter and $7.8 \mathrm{~cm}$ deep) were buried in the soil, one trap every $5 \mathrm{~m}$. Half of the pitfall traps contained an attractive solution (dark beer and preservatives; Turquin 1973), while the remaining had a non-attractive solution with a small proportion of ethylene glycol. The two types of traps were placed alternately and remained in the field for 2 weeks. Beating samples were taken on one of the days during the period that pitfall traps were in the field when the vegetation was not wet. A square $5 \mathrm{~m}$ wide was established every $15 \mathrm{~m}$ (10 sq in total per transect). In each square, a replicate of the three most dominant woody plant species was sampled (30 samples in total per transect). For each selected plant, a branch was chosen at random, a beating tray (cloth inverted pyramid $1 \mathrm{~m}$ wide and $60 \mathrm{~cm}$ deep) placed beneath and five beatings were made using a stick. A few transects had less than three woody plant species and only those species were considered. The endemic cedar, Juniperus brevifolia (Seub) Antoine (Cupressaceae), was the most common species, occurring on most transects. Each transect had its own combination of dominant plant species, a characteristic that is inherent to each site and was not dissociated in the analyses (see Gaspar et al. 2008 for further discussion). A detailed description and discussion of the sampling methods applied is presented in Gaspar et al. (2008).

All Araneae, Opiliones, Pseudoscorpiones, Myriapoda and Insecta (excluding Diptera and Hymenoptera) were considered for this study. Several taxonomists (see Acknowledgments) checked the identifications made.

\section{Data analyses}

Analyses were conducted exclusively at the fragment scale, as it is the only effective unit of conservation management applicable to these native forests. Connectivity issues for the reserve selection of the fragments were not taken into account in this study.

Abundance matrices of the arthropod species found in each native forest fragment were used to determine the minimum set of fragments needed for arthropod conservation. The resulted set of fragments found to achieve the required target will be designated hereafter as a 'solution'. Analyses were conducted using all data combined and also using different subsets categorised by: (a) taxonomic level (species, genus, family and order), (b) taxonomic order (Coleoptera, Hemiptera, Araneae and Lepidoptera; using the four most diverse orders - the remaining orders were not considered in this category because they had fewer than 20 species each, but they were included in the other categories), (c) trophic group (predator, herbivore, saprophage), (d) colonization status (endemic, i.e. species restricted to the Azores; indigenous, i.e. native species including endemics), (e) vertical strata (soil, canopy; taking into account the sampling method used-pitfall or beating) and (f) dispersal ability (high, low; based on the flight or ballooning capacities of the species). Therefore, in total, 18 datasets (one dataset with all data combined and 17 subsets for the categories considered) were analysed. This way, it was possible to evaluate if different arthropod groups would show solutions with distinct minimum sets of areas. A distinction was made between the overall dataset- 'all', and the species dataset-'species'. The latter includes solely the species that are effectively named, while the overall morphospecies database also includes species that need to be confirmed and new species that are waiting to be described (which is commonly a slow process). The use of both datasets in this study has relevance for reserve selection: unnamed morphospecies are not used in the selection of priority areas for conservation in the Azores and they cannot be legally included in conservation plans. However, in this case, there is confidence that the unnamed morphospecies correspond effectively to species. Thus, analyses were made for both datasets to see if there were differences in the results and if a different conservation approach in relation to unnamed species should be applied in the future. Hereafter, when referring solely to the named species, the term 'species dataset' will be used.

In order to determine the number of fragments needed to satisfy a given species occurrence requirement, linear optimisation problems were solved using the Cplex software (ILOG 2001). Basically, in such problems, an objective function is maximised or minimised subject to constraints (targets). Runs are then performed until all alternative optimal solutions are given. In this study, a minimisation problem was created by minimising the number of fragments selected; and four constraints were applied independently, so that all species were represented at least once (the so-called 'species set covering problem', for a review see Hamaide et al. 2006) and every species had a representation of at least $20 \%$ (low representation), $50 \%$ (medium representation) and $80 \%$ (high representation) of its total abundance. This way, it was possible to evaluate the extent of conservation area required when the representation of the species threshold was continuously increased.

Species accumulation curves were used to compare the number of species that would be included in a given set of areas selected by a complementarity method with the number of species that would be included in an equal number of areas taken at random. For both the entire 
dataset and the endemic species, we constructed accumulation curves based on sub-optimal complementary selection of areas at increasing number of selected fragments, and compared them with randomized species accumulation curves of the fragments. The optimal complementary selection of areas, as it determines the solution set of areas at only one step, would not be adequate for this purpose. The EstimateS 7.5 program (Colwell 2005) was used to calculate expected species accumulation curves (Mao Tau) and their $95 \%$ confidence intervals.

Irreplaceability in a conservation planning exercise was firstly defined by Pressey et al. (1994) as the frequency of a given site being chosen in possible alternative solutions that reach the defined conservation targets. However, as recognised by the authors, this definition had the problem of redundancy; that is, even sites that were not crucial to achieve the target would have some irreplaceability value. Ferrier et al. (2000) then refined the measure as the frequency that a given site would need to be chosen (i.e. be crucial) in possible alternative solutions to ensure that the conservation targets are achieved.

An algorithm was coded in Java software (available from P Cardoso) and was used to calculate the irreplaceability of each fragment. Basically, the algorithm uses targets and looks for all possible alternative solutions in the same way as the linear optimisation algorithms do. It is distinguished from the minimisation problems by the fact that not only is a minimum set of fragments determined. The program will also look for other alternative solutions with higher numbers of sites as long as, given the fragments selected, all of them are absolutely required to accomplish the desired target. This accounts for the flexibility that solutions should have: a site found to be irreplaceable but difficult or costly to preserve in a minimum solution may be replaceable with two other sites in a larger solution. The program runs 10,000 times and from the alternative solutions found, it calculates the percentage of times that a site was selected, giving the irreplaceability value for that site. The value ranges from 0 if the site is redundant in all cases to 100 if it is absolutely irreplaceable. The program was used for the same datasets and the four constraints applied to the linear optimisation problems.

Several minimum optimal solutions are often possible, which later offers the chance to replace one optimal solution set by another if a previous selection is found to be very difficult or costly to maintain. Here it is proposed that a measure of biotic integrity is used to distinguish amongst these solutions on the basis of the ability of a site to ensure the persistence of populations. This may help to decide which optimal solution to choose and thus reduce the risk of a set of priority areas being considered ineffective after it has been implemented for conservation action. The biotic integrity index (IBI) developed by Cardoso et al. (2007) was calculated for each forest fragment studied. This index was created based on the epigean arthropods of the Azorean native forests by determining biotic parameters that could be highly influenced by disturbance. Seven metrics were considered for the IBI, three were found to be negatively related to disturbance: (1) proportion of endemic species, (2) proportion of predator species and (3) proportion of predator individuals; while four metrics were found to be positively related to disturbance: (4) proportion of non-endemic native species, (5) proportion of introduced individuals, (6) proportion of herbivore individuals and (7) proportion of saprophage species (for more details see Cardoso et al. 2007). A score from 0 (low biotic integrity) to 2 (high biotic integrity) was defined for each metric and the total IBI value (ranging from 0-14) was determined by the sum of the individual scores. A graphical representation of IBI was also proposed by Cardoso et al. (2007) and applied in the present work.

\section{Results}

A total of 91,155 arthropod individuals distributed amongst 396 morphospecies, 321 species, 240 genera, 103 families and 20 orders were recorded in 18 native forest fragments of the Azores (Table 2).

Nearly $40 \%$ (151 spp) of the species studied occurred in only one fragment (Fig. 1). And more than half of the species $(52 \%)$ were present in one or two fragments (Fig. 1).

The randomised species accumulation curve and the curve based on complementary (sub-optimal) selection of

Table 2 Species richness and abundance for the different arthropod categories studied (all data combined, taxonomic order, trophic group, colonization status, vertical strata and dispersal ability)

\begin{tabular}{lll}
\hline & Richness & Abundance \\
\hline All & 396 & 91155 \\
Coleoptera & 117 & 5265 \\
Hemiptera & 83 & 20160 \\
Araneae & 68 & 23628 \\
Lepidoptera & 58 & 19723 \\
Herbivore & 180 & 44795 \\
Predator & 147 & 34887 \\
Saprophage & 57 & 9838 \\
Indigenous & 230 & 79664 \\
Endemic & 99 & 43630 \\
Soil & 265 & 25600 \\
Canopy & 261 & 65555 \\
High dispersal & 265 & 56353 \\
Low dispersal & 131 & 34802 \\
\hline
\end{tabular}




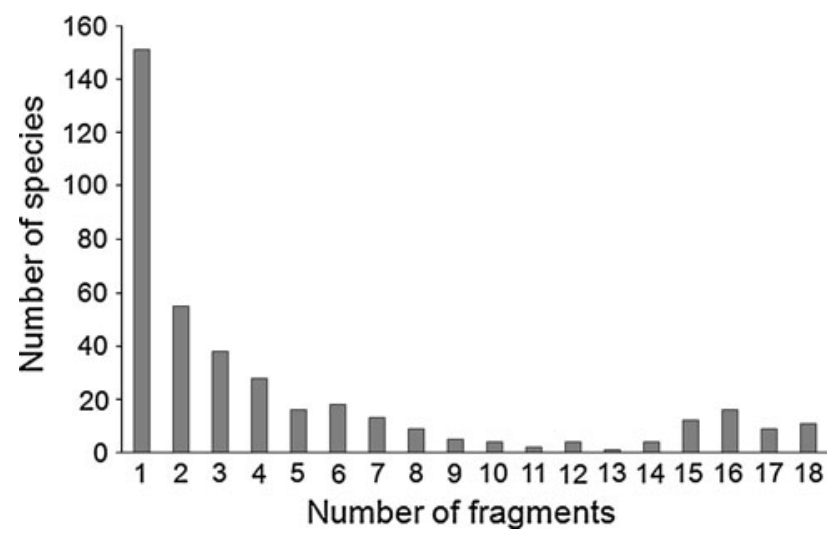

Fig. 1 Distribution range of the species for the native forest fragments for the largest dataset studied

areas for the overall dataset did not show significant differences in the total number of species preserved for 17 fragments (Fig. 2) since this corresponded to almost the totality of the fragments. However, for endemic species, 11 fragments chosen by a complementarity method would preserve significantly more species ( $99 \mathrm{spp}$ ) than at random ( $85 \pm 8$ spp, Fig. 2). The largest differences were observed for intermediate values and particularly for all data. If, for example, only five fragments could be chosen, the optimised choice would preserve $303 \mathrm{spp}$ while a random selection of areas would only protect $235 \pm 17 \mathrm{spp}$ (Fig. 2). Therefore, the complementarity method selected areas more efficiently, including more species than would be protected by a random selection.

The optimal solutions determined using linear optimisation problems for different categories of arthropods and targets are shown in Table $3 \mathrm{a}-\mathrm{g}$.

For most of the arthropod datasets analysed, only one optimal solution was found for each species representation

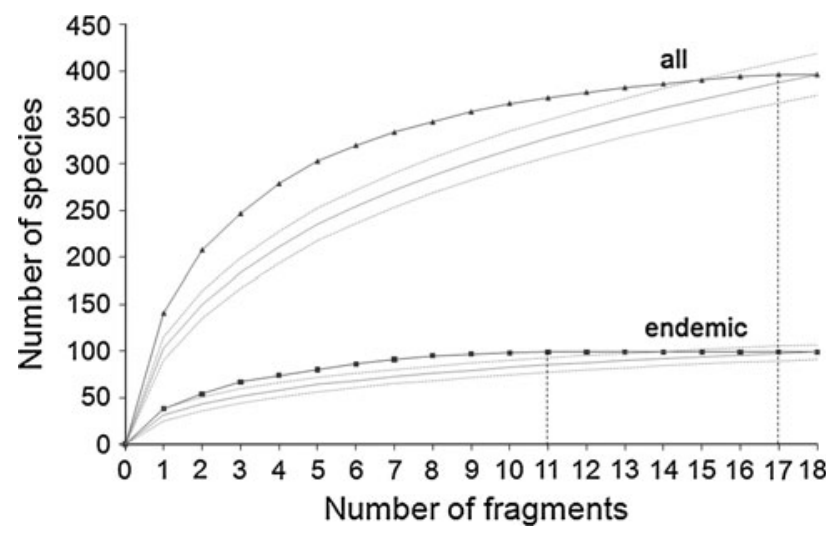

Fig. 2 Comparison between the randomised (solid grey, with 95\% confidence intervals) and the complementarity (dark) accumulation curves for the observed number of species. Results are shown for all arthropods (top) and endemics (bottom). Vertical lines indicate the minimum number of fragments needed so that all species are represented at least once target. Moreover, the presence and the $20 \%$ abundance targets gave similar optimal solutions for most of the groups considered. To achieve a high representation of all species ( $80 \%$ abundance target), all fragments were found to be necessary. The only exceptions were observed for the trophic group saprophages (17 fragments needed, Table $3 \mathrm{~d}$ ), the taxonomic levels family and order (17 and 16 fragments, Table $3 \mathrm{~b}$ ) and the taxonomic order Araneae (17 fragments, Table 3c). When 17 fragments or less were needed to achieve a given target, the largest fragment on Terceira island, TESB, was commonly considered redundant (Table 3a-g). Regardless of the dataset or target considered, with the exception of the taxonomic levels family and order and the taxonomic order Araneae, at least one fragment on each island was required for the minimum solution (Table 3a-g).

Considering the largest dataset in particular (Table 3a), the fragment TESB is dispensable to accomplish the single occurrence and the $20 \%$ abundance targets, while all fragments were needed when 50 or $80 \%$ targets were required (Table 3a).

The higher the taxonomic level considered, from the morphospecies (all, Table 3a) to the order level (Table 3b), the fewer the number of fragments needed and the more optimal solutions available.

The most diverse order, Coleoptera, was the taxonomic group that needed the greatest number of fragments for the minimum solution using any of the targets, while Araneae required a smaller number of fragments and had more alternative solutions (Table 3c). The three largest fragments of Terceira island, TESB, TEBF and TEGM, were excluded from the minimum solution for Coleoptera using presence and $20 \%$ abundance targets, but for 50 or $80 \%$ targets all fragments were necessary (Table 3c). For Araneae, only nine fragments were needed for the single occurrence target, and 13 fragments were sufficient to achieve the 50\% abundance target. All fragments of Terceira island except the smallest one, TEPG, were found to be replaceable or unnecessary for the presence and up to $50 \%$ abundance targets (Table $3 \mathrm{c}$ ).

The indigenous species showed the same pattern as the overall dataset: for presence and $20 \%$ abundance targets, TESB was not essential, for 50 and $80 \%$ targets all areas were needed (Table 3e). Considering only endemics, 11 fragments were sufficient to guarantee the presence of all species and 13 fragments ensured $20 \%$ abundance representation (Table 3e).

Regardless of the constraint used, all fragments were needed for canopy arthropods, while for soil arthropods TESB was not necessary for the first three thresholds (P/A, 20\%, 50\%; Table 3f).

Arthropods with low dispersal ability showed smaller minimum solution sets and had more alternative solutions 
Table 3 Minimum forest fragments needed so that all arthropod species occur at least once (presence/absence, P/A), or are represented by an abundance of 20,50 or $80 \%$

\begin{tabular}{|c|c|c|c|c|c|c|c|c|c|c|c|c|c|}
\hline \multirow[t]{2}{*}{ Fragment } & & \multicolumn{6}{|c|}{ All $(n=396)$} & & \multicolumn{5}{|c|}{ Species $(n=321)$} \\
\hline & & \multirow[t]{2}{*}{$\mathrm{P} / \mathrm{A}$} & \multirow[t]{2}{*}{$20 \%$} & \multicolumn{3}{|c|}{$50 \%$} & \multicolumn{2}{|l|}{$80 \%$} & $\mathrm{P} / \mathrm{A}$ & \multicolumn{2}{|l|}{$20 \%$} & $50 \%$ & \multirow[t]{2}{*}{$80 \%$} \\
\hline \multicolumn{11}{|l|}{ (a) } & & & \\
\hline FLMO & & • & $\bullet$ & & $\bullet$ & & $\bullet$ & & $\bullet$ & $\bullet$ & & $\bullet$ & $\bullet$ \\
\hline FLFR & & $\bullet$ & $\bullet$ & & $\bullet$ & & $\bullet$ & & $\bullet$ & $\bullet$ & & $\bullet$ & $\bullet$ \\
\hline TESB & & & & & $\bullet$ & & $\bullet$ & & & & & & $\bullet$ \\
\hline TEBF & & • & $\bullet$ & & $\bullet$ & & $\bullet$ & & $\bullet$ & $\bullet$ & & $\bullet$ & $\bullet$ \\
\hline TEGM & & $\bullet$ & $\bullet$ & & $\bullet$ & & $\bullet$ & & $\bullet$ & $\bullet$ & & $\bullet$ & $\bullet$ \\
\hline TETB & & • & $\bullet$ & & $\bullet$ & & $\bullet$ & & $\bullet$ & $\bullet$ & & $\bullet$ & $\bullet$ \\
\hline TEPG & & $\bullet$ & $\bullet$ & & $\bullet$ & & $\bullet$ & & $\bullet$ & $\bullet$ & & $\bullet$ & $\bullet$ \\
\hline PIMP & & $\bullet$ & $\bullet$ & & $\bullet$ & & $\bullet$ & & $\bullet$ & $\bullet$ & & $\bullet$ & $\bullet$ \\
\hline PILC & & $\bullet$ & $\bullet$ & & $\bullet$ & & $\bullet$ & & $\bullet$ & $\bullet$ & & $\bullet$ & $\bullet$ \\
\hline PICA & & $\bullet$ & $\bullet$ & & $\bullet$ & & $\bullet$ & & $\bullet$ & $\bullet$ & & $\bullet$ & $\bullet$ \\
\hline FACA & & $\bullet$ & $\bullet$ & & $\bullet$ & & $\bullet$ & & $\bullet$ & $\bullet$ & & $\bullet$ & $\bullet$ \\
\hline FACF & & $\bullet$ & $\bullet$ & & $\bullet$ & & $\bullet$ & & $\bullet$ & $\bullet$ & & $\bullet$ & $\bullet$ \\
\hline SJTO & & $\bullet$ & $\bullet$ & & $\bullet$ & & $\bullet$ & & $\bullet$ & $\bullet$ & & $\bullet$ & $\bullet$ \\
\hline SJPI & & $\bullet$ & $\bullet$ & & $\bullet$ & & $\bullet$ & & $\bullet$ & $\bullet$ & & $\bullet$ & $\bullet$ \\
\hline MIAT & & $\bullet$ & $\bullet$ & & $\bullet$ & & $\bullet$ & & $\bullet$ & $\bullet$ & & $\bullet$ & $\bullet$ \\
\hline MIGR & & $\bullet$ & $\bullet$ & & $\bullet$ & & $\bullet$ & & $\bullet$ & $\bullet$ & & $\bullet$ & $\bullet$ \\
\hline MIPV & & $\bullet$ & $\bullet$ & & $\bullet$ & & $\bullet$ & & $\bullet$ & $\bullet$ & & $\bullet$ & $\bullet$ \\
\hline MAPA & & $\bullet$ & $\bullet$ & & $\bullet$ & & $\bullet$ & & $\bullet$ & $\bullet$ & & $\bullet$ & $\bullet$ \\
\hline min. sol. & & 17 & 17 & & 18 & & 18 & & 17 & 17 & & 17 & 18 \\
\hline no. sols. & & 1 & 1 & & 1 & & 1 & & 1 & 1 & & 1 & 1 \\
\hline $\mathrm{IR}=100$ & & 17 & 17 & & 18 & & 18 & & 17 & 17 & & 17 & 18 \\
\hline \multirow[t]{2}{*}{ Fragment } & \multicolumn{4}{|c|}{ Genus $(n=240)$} & & \multicolumn{4}{|c|}{ Family $(n=103)$} & \multicolumn{4}{|c|}{ Order $(n=20)$} \\
\hline & $\mathrm{P} / \mathrm{A}$ & $20 \%$ & $50 \%$ & $80 \%$ & & $\mathrm{P} / \mathrm{A}$ & $20 \%$ & $50 \%$ & $80 \%$ & $\mathrm{P} / \mathrm{A}$ & $20 \%$ & $50 \%$ & $80 \%$ \\
\hline \multicolumn{14}{|l|}{ (b) } \\
\hline FLMO & $\bullet$ & $\bullet$ & $\bullet$ & $\bullet$ & & X & & $X$ & $\bullet$ & & $X$ & & $\bullet$ \\
\hline FLFR & $\bullet$ & $\bullet$ & $\bullet$ & $\bullet$ & & $\bullet$ & $\bullet$ & $\bullet$ & $\bullet$ & & $X$ & $X$ & $\bullet$ \\
\hline TESB & & & & $\bullet$ & & & & $X$ & $\bullet$ & $\mathrm{X}$ & $X$ & o & $X$ \\
\hline TEBF & & & & $\bullet$ & & & & $\mathrm{X}$ & $\bullet$ & & & & $X$ \\
\hline TEGM & $\bullet$ & $\bullet$ & $\bullet$ & $\bullet$ & & & & $\bullet$ & $\bullet$ & & & & $X$ \\
\hline TETB & $\bullet$ & $\bullet$ & $\bullet$ & $\bullet$ & & $\bullet$ & • & $\bullet$ & • & & $X$ & & $\bullet$ \\
\hline TEPG & $\bullet$ & $\bullet$ & $\bullet$ & $\bullet$ & & & & $X$ & $\bullet$ & & $X$ & o & $\bullet$ \\
\hline PIMP & $\bullet$ & - & $\bullet$ & $\bullet$ & & $\bullet$ & $\bullet$ & $\bullet$ & $\bullet$ & & $\bullet$ & o & $\bullet$ \\
\hline PILC & & & $\bullet$ & $\bullet$ & & • & • & • & • & & $\mathrm{X}$ & $X$ & $\bullet$ \\
\hline PICA & • & $\bullet$ & $\bullet$ & • & & & & • & • & & & o & $\bullet$ \\
\hline FACA & $\bullet$ & • & $\bullet$ & $\bullet$ & & & & $X$ & & & & $X$ & $X$ \\
\hline FACF & $\bullet$ & $\bullet$ & $\bullet$ & $\bullet$ & & $\bullet$ & - & $\bullet$ & $\bullet$ & & & $X$ & $\bullet$ \\
\hline SJTO & $\bullet$ & • & $\bullet$ & $\bullet$ & & X & o & $\bullet$ & $\bullet$ & & $\bullet$ & $X$ & $\bullet$ \\
\hline SJPI & $\bullet$ & $\bullet$ & $\bullet$ & $\bullet$ & & & & $X$ & • & & $X$ & $X$ & $X$ \\
\hline MIAT & $\bullet$ & $\bullet$ & $\bullet$ & $\bullet$ & & $\bullet$ & • & $\bullet$ & $\bullet$ & & $X$ & $X$ & $\bullet$ \\
\hline MIGR & $\bullet$ & • & $\bullet$ & • & & $X$ & & • & $\bullet$ & & & $X$ & $X$ \\
\hline MIPV & $\bullet$ & $\bullet$ & $\bullet$ & $\bullet$ & & $\bullet$ & • & $\bullet$ & $\bullet$ & $X$ & $X$ & $\bullet$ & $\bullet$ \\
\hline MAPA & $\bullet$ & • & $\bullet$ & $\bullet$ & & • & • & • & $\bullet$ & • & $X$ & • & $\bullet$ \\
\hline
\end{tabular}


Table 3 continued

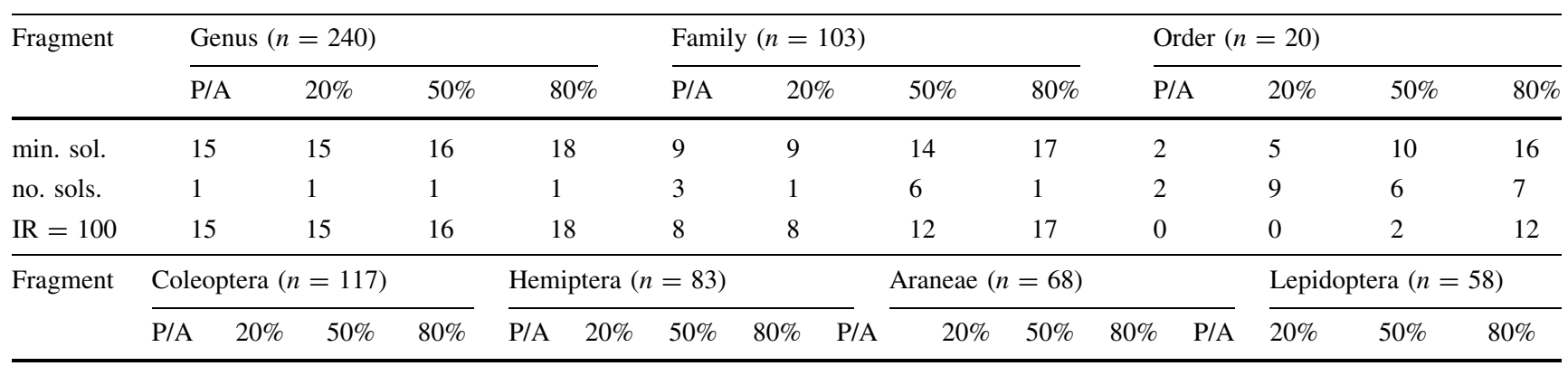

(c)

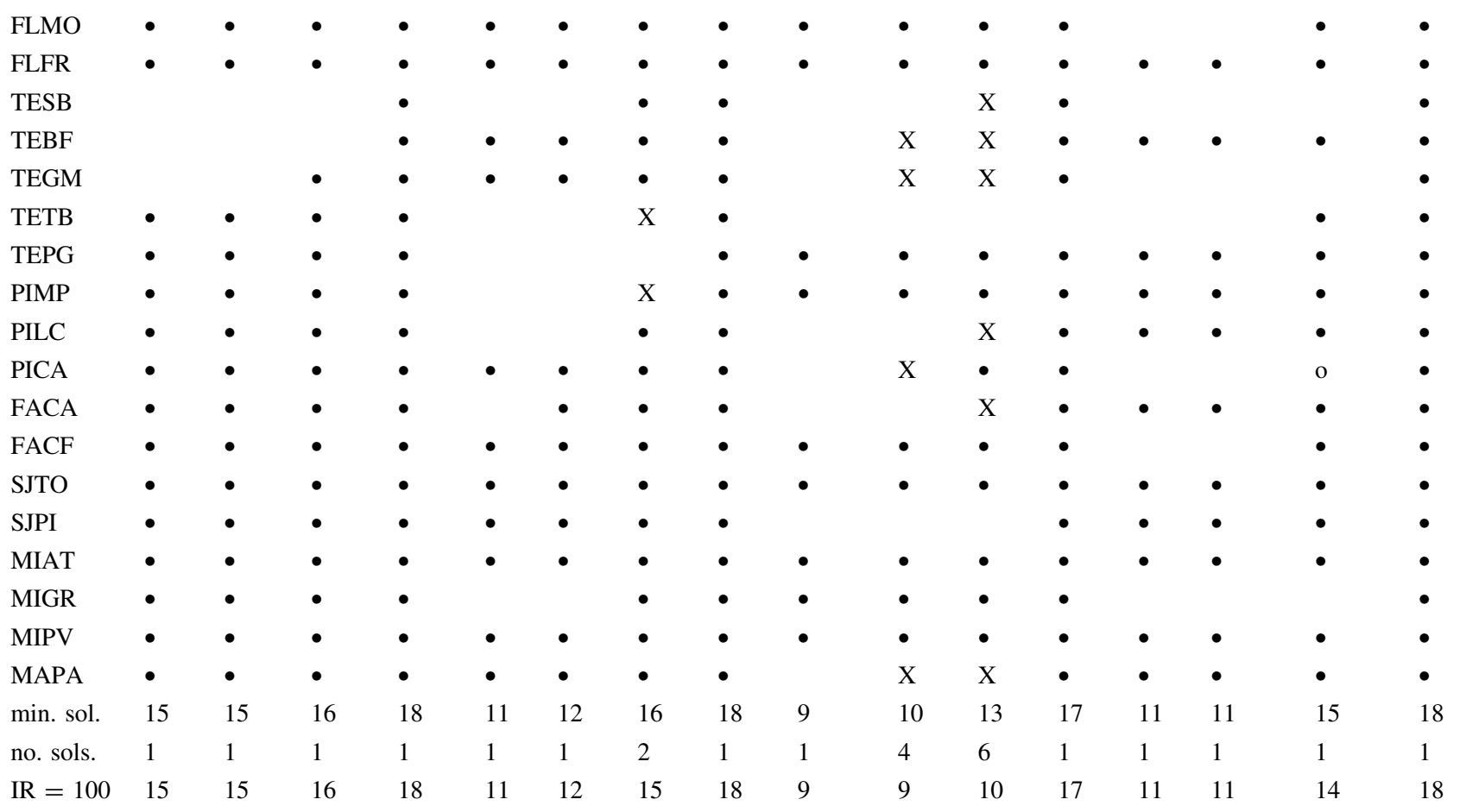

\begin{tabular}{|c|c|c|c|c|c|c|c|c|c|c|c|c|}
\hline \multirow[t]{2}{*}{ Fragment } & \multicolumn{4}{|c|}{ Herbivore $(n=180)$} & \multicolumn{4}{|c|}{ Predator $(n=147)$} & \multicolumn{4}{|c|}{ Saprophage $(n=57)$} \\
\hline & $\mathrm{P} / \mathrm{A}$ & $20 \%$ & $50 \%$ & $80 \%$ & $\mathrm{P} / \mathrm{A}$ & $20 \%$ & $50 \%$ & $80 \%$ & $\mathrm{P} / \mathrm{A}$ & $20 \%$ & $50 \%$ & $80 \%$ \\
\hline \multicolumn{13}{|l|}{ (d) } \\
\hline FLMO & $\bullet$ & $\bullet$ & $\bullet$ & $\bullet$ & $\bullet$ & $\bullet$ & $\bullet$ & $\bullet$ & $\bullet$ & $\bullet$ & $\bullet$ & $\bullet$ \\
\hline FLFR & $\bullet$ & $\bullet$ & $\bullet$ & $\bullet$ & $\bullet$ & $\bullet$ & $\bullet$ & $\bullet$ & $\bullet$ & $\bullet$ & $\bullet$ & $\bullet$ \\
\hline TESB & & & $\bullet$ & $\bullet$ & & & & $\bullet$ & & & & $\bullet$ \\
\hline TEBF & $\bullet$ & $\bullet$ & $\bullet$ & $\bullet$ & $\bullet$ & $\bullet$ & $\bullet$ & $\bullet$ & & & $X$ & $\bullet$ \\
\hline TEGM & $\bullet$ & $\bullet$ & $\bullet$ & $\bullet$ & & & $\bullet$ & $\bullet$ & $\bullet$ & $\bullet$ & $\bullet$ & $\bullet$ \\
\hline TETB & & & $\bullet$ & $\bullet$ & $\bullet$ & $\bullet$ & $\bullet$ & $\bullet$ & & $\bullet$ & $\bullet$ & $\bullet$ \\
\hline TEPG & $\bullet$ & $\bullet$ & $\bullet$ & $\bullet$ & $\bullet$ & $\bullet$ & $\bullet$ & $\bullet$ & $\bullet$ & $\bullet$ & $\bullet$ & $\bullet$ \\
\hline PIMP & $\bullet$ & $\bullet$ & $\bullet$ & $\bullet$ & $\bullet$ & $\bullet$ & $\bullet$ & • & & & $X$ & $\bullet$ \\
\hline PILC & $\bullet$ & • & $\bullet$ & $\bullet$ & $\bullet$ & • & $\bullet$ & $\bullet$ & & & $X$ & $\bullet$ \\
\hline PICA & $\bullet$ & • & $\bullet$ & $\bullet$ & $\bullet$ & $\bullet$ & $\bullet$ & - & $\bullet$ & $\bullet$ & $\bullet$ & $\bullet$ \\
\hline FACA & $\bullet$ & $\bullet$ & $\bullet$ & $\bullet$ & • & • & $\bullet$ & • & & & $X$ & $\bullet$ \\
\hline FACF & $\bullet$ & $\bullet$ & $\bullet$ & $\bullet$ & $\bullet$ & $\bullet$ & $\bullet$ & - & • & $\bullet$ & $\bullet$ & $\bullet$ \\
\hline SJTO & $\bullet$ & $\bullet$ & • & $\bullet$ & $\bullet$ & $\bullet$ & $\bullet$ & • & $\bullet$ & $\bullet$ & $\bullet$ & • \\
\hline SJPI & $\bullet$ & • & • & $\bullet$ & $\bullet$ & $\bullet$ & $\bullet$ & • & $\bullet$ & $\bullet$ & $\bullet$ & • \\
\hline MIAT & $\bullet$ & • & $\bullet$ & $\bullet$ & • & • & • & • & • & • & • & $\bullet$ \\
\hline
\end{tabular}


Table 3 continued

\begin{tabular}{|c|c|c|c|c|c|c|c|c|c|c|c|c|}
\hline \multirow[t]{2}{*}{ Fragment } & \multicolumn{4}{|c|}{ Herbivore $(n=180)$} & \multicolumn{4}{|c|}{ Predator $(n=147)$} & \multicolumn{4}{|c|}{ Saprophage $(n=57)$} \\
\hline & $\mathrm{P} / \mathrm{A}$ & $20 \%$ & $50 \%$ & $80 \%$ & $\mathrm{P} / \mathrm{A}$ & $20 \%$ & $50 \%$ & $80 \%$ & $\mathrm{P} / \mathrm{A}$ & $20 \%$ & $50 \%$ & $80 \%$ \\
\hline MIGR & $\bullet$ & $\bullet$ & $\bullet$ & $\bullet$ & $\bullet$ & $\bullet$ & $\bullet$ & $\bullet$ & & & $\mathrm{X}$ & \\
\hline MIPV & $\bullet$ & $\bullet$ & $\bullet$ & $\bullet$ & $\bullet$ & $\bullet$ & $\bullet$ & $\bullet$ & & & $\bullet$ & $\bullet$ \\
\hline MAPA & $\bullet$ & $\bullet$ & $\bullet$ & $\bullet$ & $\bullet$ & $\bullet$ & $\bullet$ & $\bullet$ & $\bullet$ & $\bullet$ & $\bullet$ & $\bullet$ \\
\hline min. sol. & 16 & 16 & 18 & 18 & 16 & 16 & 17 & 18 & 10 & 11 & 14 & 17 \\
\hline no. sols. & 1 & 1 & 1 & 1 & 1 & 1 & 1 & 1 & 1 & 1 & 6 & 1 \\
\hline $\mathrm{IR}=100$ & 16 & 16 & 18 & 18 & 16 & 16 & 17 & 18 & 10 & 11 & 12 & 17 \\
\hline \multirow[t]{2}{*}{ Fragment } & \multicolumn{6}{|c|}{ Indigenous $(n=230)$} & \multicolumn{6}{|c|}{ Endemic $(n=99)$} \\
\hline & & & $20 \%$ & & $50 \%$ & $80 \%$ & & $\mathrm{P} / \mathrm{A}$ & $20 \%$ & & $50 \%$ & $80 \%$ \\
\hline \multicolumn{13}{|l|}{ (e) } \\
\hline FLMO & \multicolumn{2}{|c|}{$\bullet$} & $\bullet$ & \multicolumn{2}{|r|}{$\bullet$} & $\bullet$ & \multicolumn{2}{|r|}{$\bullet$} & $\bullet$ & \multicolumn{2}{|r|}{$\bullet$} & $\bullet$ \\
\hline FLFR & \multicolumn{2}{|c|}{$\bullet$} & $\bullet$ & \multicolumn{2}{|r|}{$\bullet$} & $\bullet$ & & & $X$ & \multicolumn{2}{|r|}{$\bullet$} & $\bullet$ \\
\hline TESB & & & & \multicolumn{2}{|r|}{$\bullet$} & $\bullet$ & & & & \multicolumn{2}{|r|}{$\bullet$} & $\bullet$ \\
\hline TEBF & \multicolumn{2}{|c|}{$\bullet$} & $\bullet$ & \multicolumn{2}{|r|}{$\bullet$} & $\bullet$ & & o & $X$ & & $\bullet$ & $\bullet$ \\
\hline TEGM & & & $\bullet$ & & $\bullet$ & $\bullet$ & & & & & & $\bullet$ \\
\hline TETB & & & $\bullet$ & & $\bullet$ & $\bullet$ & & & $\bullet$ & & $\bullet$ & $\bullet$ \\
\hline TEPG & & & $\bullet$ & & $\bullet$ & $\bullet$ & & $\bullet$ & $\bullet$ & & $\bullet$ & $\bullet$ \\
\hline PIMP & & & $\bullet$ & & $\bullet$ & $\bullet$ & & $\bullet$ & $\bullet$ & & $\bullet$ & $\bullet$ \\
\hline PILC & & & $\bullet$ & & $\bullet$ & $\bullet$ & & & & & $\bullet$ & $\bullet$ \\
\hline PICA & & & $\bullet$ & & $\bullet$ & $\bullet$ & & $\bullet$ & $\bullet$ & & $\bullet$ & $\bullet$ \\
\hline FACA & & & $\bullet$ & & $\bullet$ & $\bullet$ & & & $\bullet$ & & $\bullet$ & $\bullet$ \\
\hline FACF & & & $\bullet$ & & $\bullet$ & $\bullet$ & & $\bullet$ & $\bullet$ & & $\bullet$ & $\bullet$ \\
\hline SJTO & & & $\bullet$ & & $\bullet$ & $\bullet$ & & $\bullet$ & $\bullet$ & & $\bullet$ & $\bullet$ \\
\hline SJPI & & & $\bullet$ & & $\bullet$ & $\bullet$ & & $\bullet$ & $\bullet$ & & $\bullet$ & $\bullet$ \\
\hline MIAT & & & $\bullet$ & & $\bullet$ & $\bullet$ & & $\bullet$ & $\bullet$ & & $\bullet$ & $\bullet$ \\
\hline MIGR & & & $\bullet$ & & $\bullet$ & $\bullet$ & & & & & $\bullet$ & $\bullet$ \\
\hline MIPV & & & $\bullet$ & & $\bullet$ & $\bullet$ & & $\bullet$ & $\bullet$ & & $\bullet$ & $\bullet$ \\
\hline MAPA & & & $\bullet$ & & $\bullet$ & $\bullet$ & & $\bullet$ & $\bullet$ & & $\bullet$ & $\bullet$ \\
\hline min. sol. & & & 17 & & 18 & 18 & & 11 & 13 & & 17 & 18 \\
\hline no. sols. & & & 1 & & 1 & 1 & & 1 & 2 & & 1 & 1 \\
\hline $\mathrm{IR}=100$ & & & 17 & & 18 & 18 & & 10 & 12 & & 17 & 18 \\
\hline Fragment & & $(n=$ & & & & & & Canopy ( $n$ & 61) & & & \\
\hline & & & $20 \%$ & & $50 \%$ & $80 \%$ & & $\mathrm{P} / \mathrm{A}$ & $20 \%$ & & $50 \%$ & $80 \%$ \\
\hline (f) & & & & & & & & & & & & \\
\hline FLMO & & & $\bullet$ & & $\bullet$ & $\bullet$ & & $\bullet$ & $\bullet$ & & $\bullet$ & $\bullet$ \\
\hline FLFR & & & $\bullet$ & & $\bullet$ & $\bullet$ & & $\bullet$ & $\bullet$ & & $\bullet$ & $\bullet$ \\
\hline TESB & & & & & & $\bullet$ & & $\bullet$ & $\bullet$ & & $\bullet$ & $\bullet$ \\
\hline TEBF & & & $\bullet$ & & $\bullet$ & $\bullet$ & & $\bullet$ & $\bullet$ & & $\bullet$ & $\bullet$ \\
\hline TEGM & & & $\bullet$ & & $\bullet$ & $\bullet$ & & $\bullet$ & $\bullet$ & & $\bullet$ & $\bullet$ \\
\hline TETB & & & $\bullet$ & & $\bullet$ & $\bullet$ & & $\bullet$ & $\bullet$ & & $\bullet$ & $\bullet$ \\
\hline TEPG & & & $\bullet$ & & $\bullet$ & $\bullet$ & & $\bullet$ & $\bullet$ & & $\bullet$ & $\bullet$ \\
\hline PIMP & & & $\bullet$ & & • & • & & $\bullet$ & $\bullet$ & & • & $\bullet$ \\
\hline PILC & & & $\bullet$ & & $\bullet$ & • & & $\bullet$ & $\bullet$ & & • & $\bullet$ \\
\hline PICA & & & $\bullet$ & & $\bullet$ & $\bullet$ & & $\bullet$ & $\bullet$ & & • & $\bullet$ \\
\hline FACA & & & $\bullet$ & & • & $\bullet$ & & $\bullet$ & $\bullet$ & & • & $\bullet$ \\
\hline FACF & & & $\bullet$ & & • & • & & $\bullet$ & $\bullet$ & & • & $\bullet$ \\
\hline
\end{tabular}


Table 3 continued

\begin{tabular}{|c|c|c|c|c|c|c|c|c|}
\hline \multirow[t]{2}{*}{ Fragment } & \multicolumn{4}{|c|}{ Soil $(n=265)$} & \multicolumn{4}{|c|}{ Canopy $(n=261)$} \\
\hline & P/A & $20 \%$ & $50 \%$ & $80 \%$ & $\mathrm{P} / \mathrm{A}$ & $20 \%$ & $50 \%$ & $80 \%$ \\
\hline SJTO & $\bullet$ & $\bullet$ & $\bullet$ & $\bullet$ & $\bullet$ & $\bullet$ & $\bullet$ & $\bullet$ \\
\hline SJPI & $\bullet$ & $\bullet$ & $\bullet$ & $\bullet$ & $\bullet$ & $\bullet$ & $\bullet$ & $\bullet$ \\
\hline MIAT & $\bullet$ & $\bullet$ & $\bullet$ & $\bullet$ & $\bullet$ & $\bullet$ & $\bullet$ & $\bullet$ \\
\hline MIGR & $\bullet$ & $\bullet$ & $\bullet$ & $\bullet$ & $\bullet$ & $\bullet$ & $\bullet$ & $\bullet$ \\
\hline MIPV & $\bullet$ & $\bullet$ & $\bullet$ & $\bullet$ & $\bullet$ & $\bullet$ & $\bullet$ & $\bullet$ \\
\hline MAPA & $\bullet$ & $\bullet$ & $\bullet$ & $\bullet$ & $\bullet$ & $\bullet$ & $\bullet$ & $\bullet$ \\
\hline min. sol. & 17 & 17 & 17 & 18 & 18 & 18 & 18 & 18 \\
\hline no. sols. & 1 & 1 & 1 & 1 & 1 & 1 & 1 & 1 \\
\hline $\mathrm{IR}=100$ & 17 & 17 & 17 & 18 & 18 & 18 & 18 & 18 \\
\hline \multirow[t]{2}{*}{ Fragment } & \multicolumn{4}{|c|}{ High dispersal $(n=265)$} & \multicolumn{4}{|c|}{ Low dispersal $(n=131)$} \\
\hline & $\mathrm{P} / \mathrm{A}$ & $20 \%$ & $50 \%$ & $80 \%$ & $\mathrm{P} / \mathrm{A}$ & $20 \%$ & $50 \%$ & $80 \%$ \\
\hline \multicolumn{9}{|l|}{ (g) } \\
\hline FLMO & $\bullet$ & $\bullet$ & $\bullet$ & $\bullet$ & & $\bullet$ & $\bullet$ & $\bullet$ \\
\hline FLFR & $\bullet$ & $\bullet$ & $\bullet$ & $\bullet$ & $\bullet$ & $\bullet$ & $\bullet$ & $\bullet$ \\
\hline TESB & & & $\bullet$ & $\bullet$ & & $\mathrm{X}$ & & $\bullet$ \\
\hline TEBF & $\bullet$ & $\bullet$ & $\bullet$ & $\bullet$ & $\bullet$ & $\bullet$ & $\bullet$ & $\bullet$ \\
\hline TEGM & $\bullet$ & $\bullet$ & $\bullet$ & $\bullet$ & $\bullet$ & $\bullet$ & $\bullet$ & $\bullet$ \\
\hline TETB & $\bullet$ & $\bullet$ & $\bullet$ & $\bullet$ & $\mathrm{X}$ & $\bullet$ & $\bullet$ & $\bullet$ \\
\hline TEPG & $\bullet$ & $\bullet$ & $\bullet$ & $\bullet$ & $\mathrm{X}$ & $X$ & $\bullet$ & $\bullet$ \\
\hline PIMP & $\bullet$ & $\bullet$ & $\bullet$ & $\bullet$ & $\bullet$ & $\bullet$ & $\bullet$ & $\bullet$ \\
\hline PILC & $\bullet$ & $\bullet$ & $\bullet$ & $\bullet$ & $\bullet$ & $\bullet$ & $\bullet$ & $\bullet$ \\
\hline PICA & $\bullet$ & $\bullet$ & $\bullet$ & $\bullet$ & $\bullet$ & $\bullet$ & $\bullet$ & $\bullet$ \\
\hline FACA & $\bullet$ & $\bullet$ & $\bullet$ & $\bullet$ & $\bullet$ & $\bullet$ & $\bullet$ & $\bullet$ \\
\hline FACF & $\bullet$ & $\bullet$ & $\bullet$ & $\bullet$ & $\bullet$ & $\bullet$ & $\bullet$ & $\bullet$ \\
\hline SJTO & $\bullet$ & $\bullet$ & $\bullet$ & $\bullet$ & $\bullet$ & $\bullet$ & $\bullet$ & $\bullet$ \\
\hline SJPI & $\bullet$ & $\bullet$ & $\bullet$ & $\bullet$ & $\bullet$ & $\bullet$ & $\bullet$ & $\bullet$ \\
\hline MIAT & $\bullet$ & $\bullet$ & $\bullet$ & $\bullet$ & $\bullet$ & $\bullet$ & $\bullet$ & $\bullet$ \\
\hline MIGR & $\bullet$ & $\bullet$ & $\bullet$ & $\bullet$ & $\bullet$ & $\bullet$ & $\bullet$ & $\bullet$ \\
\hline MIPV & $\bullet$ & $\bullet$ & $\bullet$ & $\bullet$ & $\bullet$ & $\bullet$ & $\bullet$ & $\bullet$ \\
\hline MAPA & $\bullet$ & $\bullet$ & $\bullet$ & $\bullet$ & $\bullet$ & $\bullet$ & $\bullet$ & $\bullet$ \\
\hline min. sol. & 17 & 17 & 18 & 18 & 15 & 17 & 17 & 18 \\
\hline no. sols. & 1 & 1 & 1 & 1 & 2 & 2 & 1 & 1 \\
\hline $\mathrm{IR}=100$ & 17 & 17 & 18 & 18 & 14 & 16 & 17 & 18 \\
\hline
\end{tabular}

The circles indicate fragments that are always chosen in a minimum solution, while the crosses show the ones that are interchangeable. Closed circles indicate the fragments that have an irreplaceable value of $100 \%(\mathrm{IR}=100)$, open circles (and crosses) those that have a IR $<100$. The number of fragments needed to accomplish the optimal solution (min. sol.), the number of alternative solutions (no. sols.) and the number of completely irreplaceable fragments $(\mathrm{IR}=100)$ are given at the bottom. Optimal solutions are shown for all groups considered. Codes for fragments as in Table 1

than high dispersal arthropods for the occurrence and $20 \%$ abundance targets (Table 3g).

The irreplaceability analyses showed that for most of the datasets and the constraints considered, all fragments had extreme values. That is, they were completely irreplaceable (IR $=100$; Table $3 \mathrm{a}-\mathrm{g}$ ) or unnecessary $(\mathrm{IR}=0)$. Exceptions to this finding were observed for the family and order taxonomic levels, the Araneae and Lepidoptera taxonomic orders, the saprophages trophic group, the endemic colonization group and the low dispersal arthropods (Table 3a-g).

In addition, the majority or all fragments had high irreplaceability (IR $>50 \%$ ) while a few or none had low irreplaceability $(\mathrm{IR}<50)$. The only exceptions to this were found for the family and order taxonomic 
Fig. 3 Location of the eighteen native forest fragments studied and the calculated value of their Index of Biotic Integrity (IBI). Each metric can range from 0 (no grey fills in the pie fraction) to 2 (both portions filled). Distances between islands were reduced for clarity. Codes of fragments as in Table 1

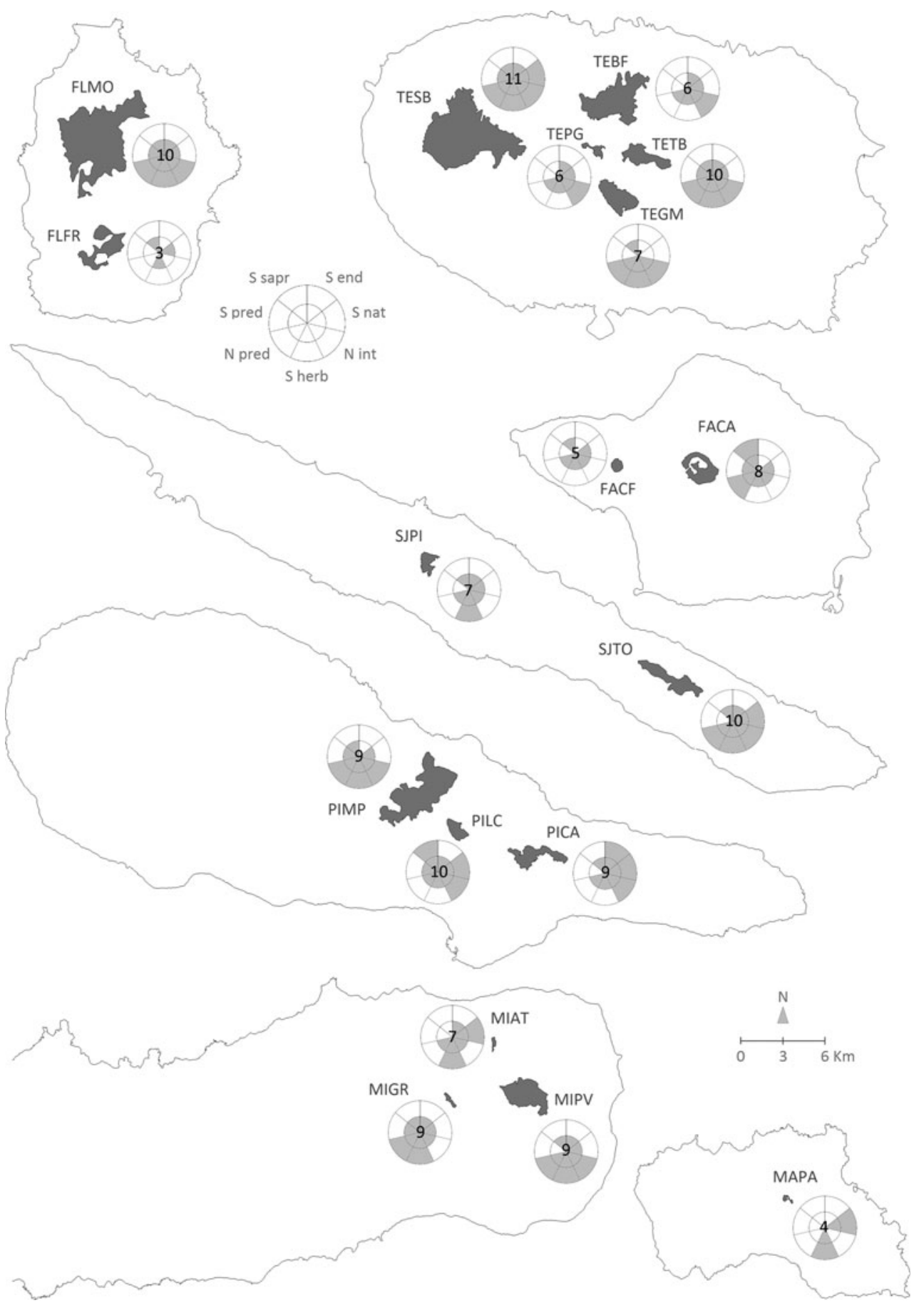

levels for presence and $20 \%$ abundance targets, where the majority of fragments had low irreplaceability value (Table 3a-g).

Although the fragment TESB was often found redundant for a minimal solution or replaceable by other alternative fragment(s), the IBI showed that it is the native forest fragment with the highest biotic integrity (Fig. 3). It is also the largest native forest area in the archipelago (Table 1, Fig. 3).

\section{Discussion}

The optimisation analyses showed that 17 out of 18 native forest fragments are required for all arthropod species to be represented at least once. This finding emphasises the unique contribution that the species richness of each fragment has for the regional diversity of the archipelago. In fact, almost half of the arthropod species studied were exclusive to a fragment. Excluding the largest fragment 
from Terceira, TESB, all fragments had exclusive species, which explains the complete irreplaceability value $(\mathrm{IR}=100)$ for all these areas and a single possible optimal solution.

Species occurrence, accounting only for the presence of the species regardless of its abundance, is a common target in conservation studies. However, it has been suggested that presence-absence data may not be robust over time for reserve selection (but see Rodrigues et al. 2000). One of the reasons is that several factors such as migration or extinction, besides intrinsic metapopulation factors, may influence the presence of the species at a given time (e.g. Fleishman et al. 2006), and different optimal solutions may be found on different time scales. Another related reason is that a solution obtained using an occurrence target does not include any requirement to ensure the viability of the species populations (e.g. Araújo and Williams 2000; Gaston et al. 2001).

The use of an abundance threshold, instead of the simple occurrence of species, reduces the flexibility of the choices and usually implies more costs as more areas are needed. Actually, abundance data are unavailable and costly to obtain in many cases. However, the abundance target has been considered one of the possible criteria to guarantee the viability of species and that can overcome the limitations of the presence target. Borges et al. (2005a), in a study developed with epigean endemic arthropods in Azorean natural pastures and native forests, suggest that the abundance targets more realistically represent the uniqueness of the sites chosen. The authors found that using the occurrence target, several sites that were considered of high conservation value by other criteria were neglected (Borges et al. 2005a).

In the present study, the optimal solution given for a $20 \%$ abundance target was found to be similar to the solution for an occurrence target. However, when a $50 \%$ abundance target or higher was imposed, all forest fragments were included in the minimum solution. Borges et al. (2005a) found similar results. Arthropod abundance of the non-exclusive species is partitioned by native fragments which explains the finding that if a high representation of species is imposed, invariably all fragments are needed. The only groups that needed less than the totality of the fragments for an $80 \%$ abundance target were the saprophages trophic group and the family and order taxonomic levels, as they are small groups occurring in all fragments, and the Araneae order since it is the most ubiquitous group of the four largest orders studied (Gaspar et al. 2008).

For the occurrence and 20\% targets, arthropods with high dispersal ability showed larger minimum solution sets and fewer alternative solutions than low dispersal arthropods. This is a counter-intuitive result and may be related with ecological constraints of some species that, although having higher dispersal ability, may not be successful in establishing viable populations in these forests.

In general, groups within the same category (e.g. comparison among Coleoptera, Hemiptera, Araneae and Lepidoptera for the taxonomic order category) gave different optimal solutions for the lower targets (occurrence and 20\% abundance). However, when a high representation of the species was imposed ( $80 \%$ abundance target), all fragments were included in the optimal solutions for all groups. But this high representation of species may be difficult to implement. Thus, for up to a medium representation of species, some caution is needed when selecting a given group for study and to infer the optimal solutions for other groups. The use of surrogates for reserve selection is addressed elsewhere (Gaspar et al. 2010), but from the present study it is possible to observe that the optimal solutions of different groups within each category do not correspond with each other. Additionally, the solutions for subsets do not agree with the optimal solutions for the overall dataset. The indigenous and high-dispersal groups are the only exceptions, but some autocorrelation may occur as they are amongst the largest subsets of the overall dataset.

For the optimisation problems where alternative solutions were found, a combination with the IBI information could be helpful to identify the most appropriate solution to guarantee sustainable populations, if other factors do not constrain the solution. For example, to achieve the preservation of $20 \%$ of all endemic species, besides the twelve irreplaceable fragments, one of the fragments FLFR or TEBF would be needed to complete the minimum solution (Table 3e). Taking into account the IBI values of each area (IBI: TEBF $=6$, FLFR $=3$, Fig. 3 ), TEBF should be preferred. Similarly, the IBI and the irreplaceable values may be helpful to choose fragments from larger solutions when there are constraints or concerns (e.g. low IBI) that impede or refrain from using the minimum solution. The IBI and the irreplaceability values can also be useful to help on the definition of the management plans for each area.

This study used standardised field data for arthropods. However, commonly, collection of new field data for a region is not possible due to time, human or financial constraints and conservationists have to deal in many cases with datasets from several sources. False absences, although they should be avoided, occur due to lack of information, even for field data. But the most serious error is false presences (Loiselle et al. 2003). This type of error is unlikely to be observed in new field data but occurs frequently in record data or distribution models. A false presence in a given area implies that that site may be erroneously chosen to represent the species, ignoring others where the species is actually present (Brooks et al. 2004). This is one of the reasons why a great effort should be 
made to include the collecting of field data in reserve design plans. For the Azores, where diversity is extremely low in relation to other archipelagos of Macaronesia and to most of the European mainland (Borges et al. 2005b), there is no reason why this should not be a requirement.

Margules and Pressey (2000) suggest that reserves will be effective in the network and through time if they meet representativeness and persistence criteria. In this case, a medium representation target for all species (50\%) and the posterior refinement of alternative optimal solutions with an index of Biotic Integrity may be one of the possible strategies to guarantee that the native forest fragments selected are both as efficient (using the minimum solutions, Rodrigues et al. 1999) and effective (using the maximum representation, Rodrigues et al. 1999) as possible for arthropod conservation. But the fact that an area is defined theoretically as a priority does not mean that it will be adequately managed to assure the preservation of biodiversity. Management plans are needed and after this, evaluation and monitoring schemes should be used to confirm that management strategies are being employed and also that our objectives of viability of populations in the selected reserve network are being met through time (Gaston and Rodrigues 2003; Jackson et al. 2004; Gaston et al. 2006). Local policies need to be taken into account when defining reserve selection and management plans. Costello and Polaski (2004), for example, applied a local strategy of dynamic selection of areas at different periods in time to address the periodic availability of money to acquire wetlands or the time necessary to change the land-use.

Based on the results obtained here, and previous studies on the local strategies for the region, suggestions are made for the steps required for the selection of areas in terrestrial biotopes of the Azores archipelago (excluding coastal areas and not taking into account connectivity issues), which may have application to other oceanic archipelagos and habitat islands:

(1) Map the land-use of all islands with updated aerial photography and complement with field verification when necessary;

(2) Define biotope and/or land-use units;

(3) Design distinct sampling methods for different taxonomic groups and different biotopes (for arthropods: pitfall and beating in native forests, pitfall and sweeping in pastures, pitfall in loose volcanic soil);

(4) Do a standardised sampling of the different patches and biotopes selected;

(5) Define a representation target (e.g. 50\% abundance target for arthropods);

(6) Determine an integrity index related to disturbance (or any other shortcut to measure disturbance). Include the index as a target in the optimisation method or, alternatively, after determining the optimal solutions, use the index to refine the different optimal solutions (IBI for arthropods);

(7) Determine optimal solutions to minimising the areas to protect (using CPLEX, LINDO or other optimisation software);

(8) Acquire areas to protect if land is private. If it is not possible to buy, choose another minimum solution. If no other optimal solutions occur, use alternative larger solutions. If the land is public, restrict the access to it so that human activities are controlled;

(9) Define the areas of the reserve network as protected areas. Maintain the monitoring programs periodically. Use a single designation to protect all areas of the same biotope, elect a single entity to be responsible for the monitoring program and management of the areas. Use the same definitions of threats for the overall region.

(10) Define specific management plans for each type of biotope (recommendations for the Azorean native forests will be published soon);

(11) Monitor the management plans. If inefficient, revise the management plans;

(12) Define sampling methods to monitor the effectiveness of the reserve network. If ineffective, select other alternative solutions from the optimal solution. If no other minimum solutions occur, use alternative larger solutions. If the reserve network is still ineffective, revise the sampling methods, sample other patches of the same biotope and repeat the optimisation analyses.

Acknowledgments We are grateful to all of the researchers that collaborated in the field and laboratory: Álvaro Vitorino, Anabela Arraiol, Ana Rodrigues, Artur Serrano, Carlos Aguiar, Catarina Melo, Francisco Dinis, Genage André, Emanuel Barcelos, Fernando Pereira, Hugo Mas, Isabel Amorim, João Amaral, Joaquín Hortal, Lara Dinis, Paula Gonçalves, Sandra Jarroca, Sérvio Ribeiro and Luís Vieira. The Forest Services provided local support on each island. Acknowledgments are due to all of the taxonomists who assisted in the identification of the morphotypes: Andrew Polaszek, Bivar Sousa, Artur Serrano, Arturo Baz, Fernando Ilharco, Henrik Enghoff, Jordi Ribes, José Quartau, Jörg Wunderlich, Mário Boieiro, Ole Karsholt, Richard Strassen, Volker Manhert and Virgílio Vieira. We thank Jon Sadler, Owen Petchey, Simone Fattorini and an anonymous referee for helpful discussions and suggestions. CG was funded by the Portuguese Fundação para a Ciência e a Tecnologia (BD/11049/2002) during her $\mathrm{PhD}$ research project and has currently a postdoctoral grant from the Azorean Fundo Regional da Ciência e Tecnologia (M3.1.7/ F/007/2009). PC is supported by Fundação para a Ciência e a Tecnologia (SFRH/BPD/40688/2007). Field work was also funded by the Azorean Direcção Regional dos Recursos Florestais (Proj. 17.01080203).

\section{References}

Araújo MB, Williams PH (2000) Selecting areas for species persistence using occurrence data. Biol Conserv 96:331-345 
Balmford A, Whitten T (2003) Who should pay for tropical conservation, and how could the costs be met? Oryx 37:238-250

Borges PAV, Serrano ARM, Quartau JA (2000) Ranking the Azorean Natural Forest Reserves for conservation using their endemic arthropods. J Insect Conserv 4:129-147

Borges PAV, Aguiar C, Amaral J, Amorim IR, André G, Arraiol A, Baz A, Dinis F, Enghoff H, Gaspar C, Ilharco F, Mahnert V, Melo C, Pereira F, Quartau JA, Ribeiro SP, Ribes J, Serrano ARM, Sousa AB, Strassen Rz, Vieira L, Vieira V, Vitorino A, Wunderlich J (2005a) Ranking protected areas in the Azores using standardised sampling of soil epigean arthropods. Biodivers Conserv 14:2029-2060

Borges PAV, Cunha R, Gabriel R, Martins AF, Silva L, Vieira V (eds) (2005b) A list of the terrestrial fauna (Mollusca and Arthropoda) and flora (Bryophyta, Pteridophyta and Spermatophyta) from the Azores. Direcção Regional de Ambiente and Universidade dos Açores, Horta, Angra do Heroísmo and Ponta Delgada

Borges PAV, Ugland KI, Dinis FO, Gaspar C (2008) Insect and spider rarity in an oceanic island (Terceira, Azores): true rare and pseudo-rare species. In: Fattorini S (ed) Insect ecology and conservation. Research Signpost, Kerala, pp 47-70

Borges PAV, Costa A, Cunha R, Gabriel R, Gonçalves V, Martins AF, Melo I, Parente M, Raposeiro P, Santos RS, Silva L, Vieira P, Vieira V (eds) (2010) A list of the terrestrial and marine biota from the Azores. Princípia, Lisboa

Brooks T, da Fonseca GAB, Rodrigues ASL (2004) Species, data, and conservation planning. Conserv Biol 18:1682-1688

Cardoso P, Borges PAV, Gaspar C (2007) Biotic integrity of the arthropod communities in the natural forests of Azores. Biodivers Conserv 16:2883-2901

Cardoso P, Lobo JM, Aranda SC, Dinis F, Gaspar C, Borges PAV (2009) A spatial scale assessment of habitat effects on arthropod communities of an oceanic island. Acta Oecol 35:590-597

Colwell RK (2005) EstimateS: statistical estimation of species richness and shared species from samples. Version 7.5. User's guide and application published at: http://purl.oclc.org/estimates

Costello C, Polasky S (2004) Dynamic reserve site selection. Resour Energy Econ 26:157-174

Dias E (1996) Vegetação Natural dos Açores: Ecologia e Sintaxonomia das Florestas Naturais. PhD Thesis, Universidade dos Açores, Angra do Heroísmo

DRA-Direcção Regional do Ambiente (2004) Plano Sectorial para a Rede Natura 2000 na Região Autónoma dos Açores. Direcção Regional do Ambiente, Açores

Emerson BC (2002) Evolution on oceanic islands: molecular phylogenetic approaches to understanding pattern and process. Mol Ecol 11:951-966

Ferrier S, Pressey RL, Barrett TW (2000) A new predictor of the irreplaceability of areas for achieving a conservation goal, its application to real-world planning, and a research agenda for further refinement. Biol Conserv 93:303-325

Fleishman E, Noss RF, Noon BR (2006) Utility and limitations of species richness metrics for conservation planning. Ecol Indic 6:543-553

Frazee SR, Cowling RM, Pressey RL, Turpie JK, Lindenberg N (2003) Estimating the costs of conserving a biodiversity hotspot: a case-study of the Cape Floristic Region, South Africa. Biol Conserv 112:275-290

Gaspar C, Borges PAV, Gaston KJ (2008) Diversity and distribution of arthropods in native forests of the Azores archipelago.
Arquipélago-Life and Marine Sciences 25:1-30 (freely available at: http://www.arquipelago.info)

Gaspar C, Gaston KJ, Borges PAV (2010) Arthropods as surrogates of diversity at different spatial scales. Biol Conserv 143:1287-1294

Gaston KJ, Rodrigues ASL (2003) Reserve selection in regions with poor biological data. Conserv Biol 17:188-195

Gaston KJ, Rodrigues ASL, van Rensburg BJ, Koleff P, Chown SL (2001) Complementary representation and zones of ecological transition. Ecol Lett 4:4-9

Gaston KJ, Charman K, Jackson SF, Armsworth PR, Bonn A, Briers RA, Callaghan CSQ, Catchpole R, Hopkins J, Kunin WE, Latham J, Opdam P, Stoneman R, Stroud DA, Tratt R (2006) The ecological effectiveness of protected areas: the United Kingdom. Biol Conserv 132:76-87

Hamaide B, ReVelle CS, Malcolm SA (2006) Biological reserves, rare species and the trade-off between species abundance and species diversity. Ecol Econ 56:570-583

ILOG (2001) CPlex 7.1. ILOG. Gentilly, France

Jackson SF, Kershaw M, Gaston KJ (2004) The performance of procedures for selecting conservation areas: waterbirds in the UK. Biol Conserv 118:261-270

Justus J, Sarkar S (2002) The principle of complementarity in the design of reserve networks to conserve biodiversity: a preliminary history. J Biosci 27:421-435

Kingsland S (2002) Designing nature reserves: adapting ecology to real-world problems. Endeavour 26:9-14

Loiselle BA, Howell CA, Graham CH, Goerck JM, Brooks T, Smith KG, Williams PH (2003) Avoiding pitfalls of using species distribution models in conservation planning. Conserv Biol 17:1591-1600

Margules CR, Pressey RL (2000) Systematic conservation planning. Nature 405:243-253

Margules C, Usher MB (1981) Criteria used in assessing wildlife conservation potential-a review. Biol Conserv 21:79-109

Nantel P, Bouchard A, Brouillet L, Hay S (1998) Selection of areas for protecting rare plants with integration of land use conflicts: a case study for the west coast of Newfoundland, Canada. Biol Conserv 84:223-234

Pressey RL, Johnson IR, Wilson PD (1994) Shades of irreplaceability: towards a measure of the contribution of sites to a reservation goal. Biodivers Conserv 3:242-262

Rodrigues ASL, Tratt R, Wheeler BD, Gaston KJ (1999) The performance of existing networks of conservation areas in representing biodiversity. Proc $\mathrm{R}$ Soc Lond $\mathrm{B}$ Bio 266: $1453-1460$

Rodrigues ASL, Gaston KJ, Gregory RD (2000) Using presenceabsence data to establish reserve selection procedures that are robust to temporal species turnover. Proc R Soc Lond B Bio 267:897-902

Strange N, Rahbek C, Jepsen JK, Lund MP (2006) Using farmland prices to evaluate cost-efficiency of national versus regional reserve selection in Denmark. Biol Conserv 128:455-466

Turquin MJ (1973) Une biocenose cavernicole originale pour le Bugey: le puits de Rappe. In: Actes du 96e Congrès national des Sociétés savantes, Toulouse, pp 235-256

Vane-Wright RI, Humphries CJ, Williams PH (1991) What to protect-systematics and the agony of choice. Biol Conserv $55: 235-254$ 